\title{
Potential for Use of Veneer-Based Multi-Material Systems in Vehicle Structures
}

\author{
David B. Käse ${ }^{1, a^{*}}$, Giovanni Piazza ${ }^{1, b}$, Dr.-Ing. Elmar Beeh ${ }^{1, c}$, \\ Prof. Dr.-Ing. Horst E. Friedrich ${ }^{1, d}$, Daniel Kohl ${ }^{2, e}$, Hoa Nguyen ${ }^{2, f}$, \\ Dr. Dirk Berthold ${ }^{3,9}$ and Claudia Burgold ${ }^{3, h}$ \\ ${ }^{1}$ Institute of Vehicle Concepts, German Aerospace Center, Pfaffenwaldring 38-40, Stuttgart, \\ Germany \\ ${ }^{2}$ Department for Cutting and Joining Manufacturing Processes, University of Kassel Kurt-Wolters- \\ Str. 3, Kassel, Germany \\ ${ }^{3}$ Wilhelm-Klauditz-Institut, Fraunhofer Institute for Wood Research, Bienroder Weg 54E, \\ Braunschweig, Germany

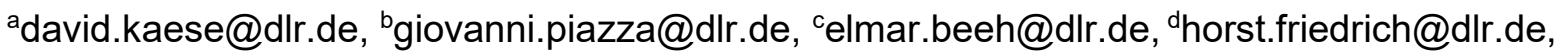 \\ ed.kohl@uni-kassel.de, ${ }^{f}$ h.nguyen@uni-kassel.de, ${ }^{9}$ dirk.berthold@wki.fraunhofer.de, \\ hclaudia.burgold@wki.fraunhofer.de
}

Keywords: vehicle construction, lightweight design, hybrid materials, veneer, beech wood

\begin{abstract}
In the past, the focus for the development of modern vehicle structures was very much on lightweight construction. However, there are increasing aspirations to develop not only light but also sustainable solutions that use resources efficiently. As a result, natural materials become more attractive compared to conventional lightweight construction materials.

The "For(s)tschritt" research project investigates the use of veneer-based multi-material systems in vehicle structures. For this purpose, various concepts were developed, ranging from a use of the material to reinforce thin sheet metals to structural components which are produced completely from wood and are only reinforced locally. In order to evaluate the aspired solutions, generic components were derived, manufactured at the Department for Cutting and Joining Manufacturing Processes of the University of Kassel (TFF) and the Fraunhofer Institute for Wood Research, Wilhelm-KlauditzInstitut (WKI), and tested at the Institute of Vehicle Concepts of the German Aerospace Center (DLR).

The advantages of the use of wood are particularly evident in structures which are subjected to bending stress and pressure loads: As a result of the lower density, they can be designed with reinforcement. This allows the second moments of inertia to be increased without affecting the weight. The disadvantages of the natural material, such as reduced reproducibility and the complex failure behaviour, are offset by systematic hybridisation of wood and the use of veneer multilayer composites.
\end{abstract}

\section{Introduction}

Despite its good specific mechanical properties and the high level of environmental sustainability, the material wood is hardly used in modern vehicle structures. The For(s)tschritt project developed concepts for the integration of veneer-based multi-material systems in vehicle structures. They are illustrated in the following example of the MAUDE vehicle concept developed at DLR.

Fig. 1 shows the concept of the MAUDE. The vehicle is made up of what is known as a drive board and a capsule. Depending on whether the vehicle is used to convey goods or passengers, various different capsules can be accommodated by the autonomous electrified drive board. This way, the same drive board can be used to convey passengers by day and goods by night, thus maximising the utilisation of the costly drive components, in particular the battery. The various different capsules must be customisable, cost-effective, light and safe for conveying passengers. In addition, low $\mathrm{CO}_{2}$ emissions during production and high recycling quotas have to be achieved [1]. 

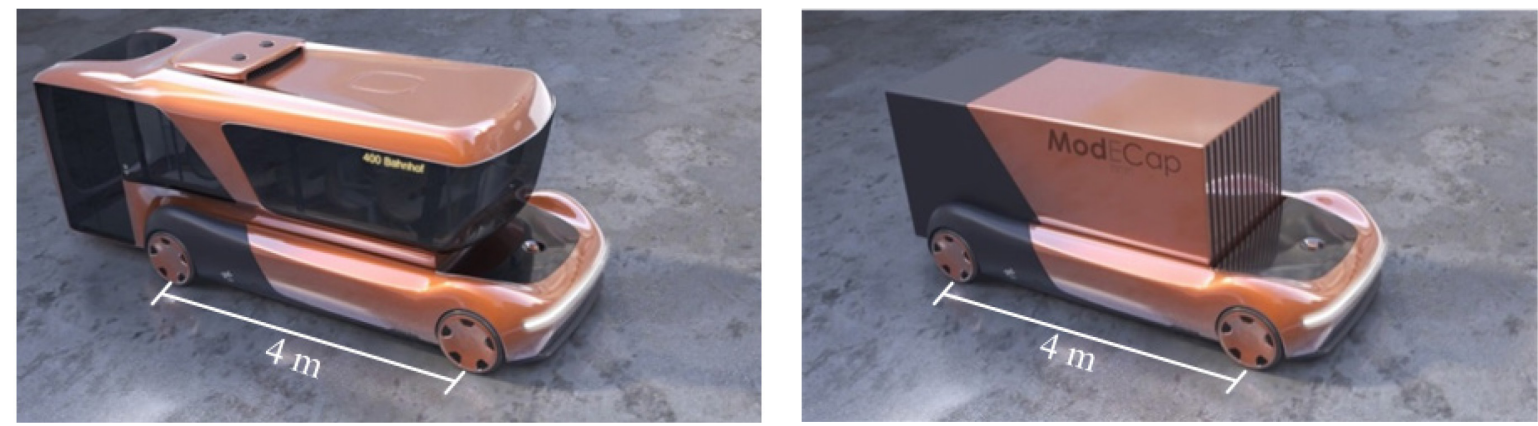

Fig. 1: MAUDE concept: Capsule for conveying passengers (left) and for transportation of goods (right)

Wood addresses many of these requirements. The material is comparable with typical technical materials, such as aluminium or magnesium, with regard to its specific properties with the grain [2]. Moreover, wood - depending on the type of wood and its origin - has good availability. Beech wood, which is used for the For(s)tschritt project, is readily available in Europe. This makes for short transportation distances and low material costs of around $0.20 € / \mathrm{kg}$ [3].

The pressures and temperatures required for producing and processing veneers are much lower than for conventional materials, such as steel. This leads to lower costs for tools and presses, lower tool wear and energy savings throughout the manufacturing process. Various methods are available for the processing of veneers. These include the manufacture of moulded wooden components in a vacuum process (vacuum bag/vacuum table), in an autoclave process and in a press process. This favours flexibility and the scalability of the production. Thanks to the very simple way in which moulded wood components are machined, e.g. milling, derivatives can be created in a simple and cost-effective manner.

Multiple challenges need to be addressed when using veneer based materials in vehicle structures. Wood can be described as a naturally grown fibre composite material which comprises a lignin matrix and reinforcing cellulose fibres. This results in anisotropic and also fluctuating material characteristics [2]. Veneer multilayer composites can be used systematically to make use of anisotropy and offset dispersive material characteristics. Moreover, the material characteristics in part depend on the wood humidity [4] and the strain rate [5]. The dependency on the strain rate can be taken into account for dimensioning - the material humidity, however, depends on the ambient humidity and is thus only predictable to a limited extent. Unprotected wood is also sensitive to environmental influences. These include, for example, moisture-related decomposition processes or mould. Appropriate constructional protection, for example using hybridisation with an aluminium outer skin, has to be provided in order to be able to use the wood material in structural applications.

\section{Experimental validation of different concepts}

The following is an explanation of a selection of the solution approaches for the use of veneer-based multi-material systems in vehicle structures, as developed within the scope of the For(s)tschritt project, using the example of MAUDE. When it comes to hybridisation of wood, the focus is placed on steel and aluminium. These material groups are established in vehicle manufacturing - therefore, existing technologies, e.g. in the field of joining technology, can be called upon. For the following concepts the metallic component was reduced significantly in comparison to the references. After mechanically separating wood and metal, the wood can be shredded and used for the particle board industry. The metal can be recycled.

For use in the cargo field, structures that are cost-effective and robust are required. Sheet steel is often used in the area of goods transportation. Sea freight containers are one example of this. In the following, a steel sheet, $2.5 \mathrm{~mm}$ in thickness, made from 1.4301 grade steel was used as the reference and substituted by a wooden composite sandwich structure without affecting the weight (see Fig. 2c). The sandwich structure could be used, for example, as the shell of a capsule for the transportation of goods. The wooden sandwich components were manufactured at TFF using a press process. Aluminium and steel sheet material was investigated as the surface layer material (see Fig. 2a). The samples were tested in the test setup shown in Fig. $2 b$. 
The trials show the high potential of aluminium-wood sandwich composites with regard to the stiffness and maximum load (see Fig. 2d). The maximum force level of variant 1 stands at more than six times that of the steel reference. This is down to the lower density of the aluminium surface layer and the resultant very thick wooden core. Variants 2 and 3 show almost identical force-displacement curves although the structure of layers in the core is different. The steel surface layers dominate the failure behaviour in this case. In comparison to variant 1 , there is also no abrupt failure.

a)

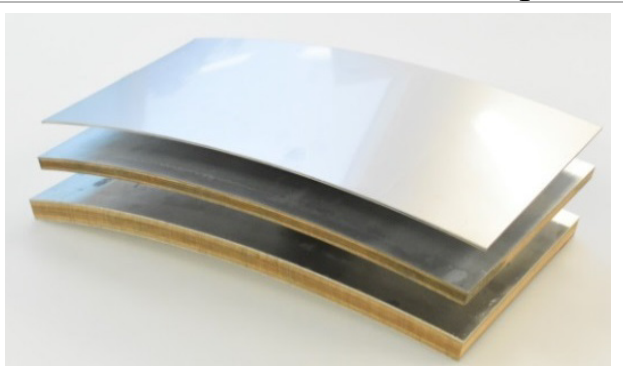

b)

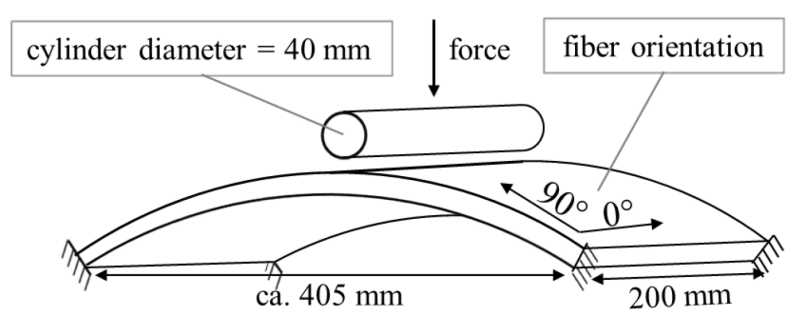

c)

\begin{tabular}{|c|c|c|c|c|c|c|c|c|c|c|c|}
\hline & Layer & 1 & 2 & 3 & 4 & 5 & 6 & 7 & 8 & 9 & 10 \\
\hline \multirow{3}{*}{ 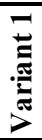 } & Material & $\mathrm{Al}$ & B & $\mathrm{B}$ & $\mathrm{B}$ & B & B & B & B & B & $\mathrm{Al}$ \\
\hline & Thickness [mm] & 1.5 & 2.0 & 2.0 & 2.0 & 2.0 & 2.0 & 2.0 & 2.0 & 2.0 & 1.0 \\
\hline & Orientation & - & $90^{\circ}$ & $90^{\circ}$ & $0^{\circ}$ & $0^{\circ}$ & $0^{\circ}$ & $0^{\circ}$ & $90^{\circ}$ & $90^{\circ}$ & - \\
\hline \multirow{3}{*}{ 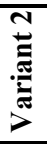 } & Material & $\mathrm{St}$ & $\mathrm{B}$ & $\mathrm{B}$ & $\mathrm{B}$ & $\mathrm{B}$ & $\mathrm{B}$ & $\mathrm{St}$ & & & \\
\hline & Thickness [mm] & 0.7 & 2.0 & 2.0 & 2.0 & 2.0 & 2.0 & 0.6 & & & \\
\hline & Orientation & - & $90^{\circ}$ & $0^{\circ}$ & $0^{\circ}$ & $0^{\circ}$ & $90^{\circ}$ & - & & & \\
\hline \multirow{3}{*}{ 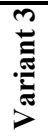 } & Material & $\mathrm{St}$ & $\mathrm{B}$ & $\mathrm{B}$ & $\mathrm{B}$ & $\mathrm{B}$ & $\mathrm{B}$ & $\mathrm{St}$ & & & \\
\hline & Thickness [mm] & 0.7 & 2.0 & 2.0 & 2.0 & 2.0 & 2.0 & 0.6 & & & \\
\hline & Orientation & - & $90^{\circ}$ & $90^{\circ}$ & $0^{\circ}$ & $90^{\circ}$ & $90^{\circ}$ & - & & & \\
\hline
\end{tabular}

\begin{tabular}{|l|c|}
\hline & Meas ure d weight $[\mathbf{k g}]$ \\
\hline Variant 1 & 1.57 \\
\hline Variant 2 & 1.53 \\
\hline Variant 3 & 1.44 \\
\hline Reference & 1.59 \\
\hline
\end{tabular}

Aluminum (AW 5754): Al; Steel (DX54D): St; Beech veneer: B; Glue: Jowat 680.20

d)

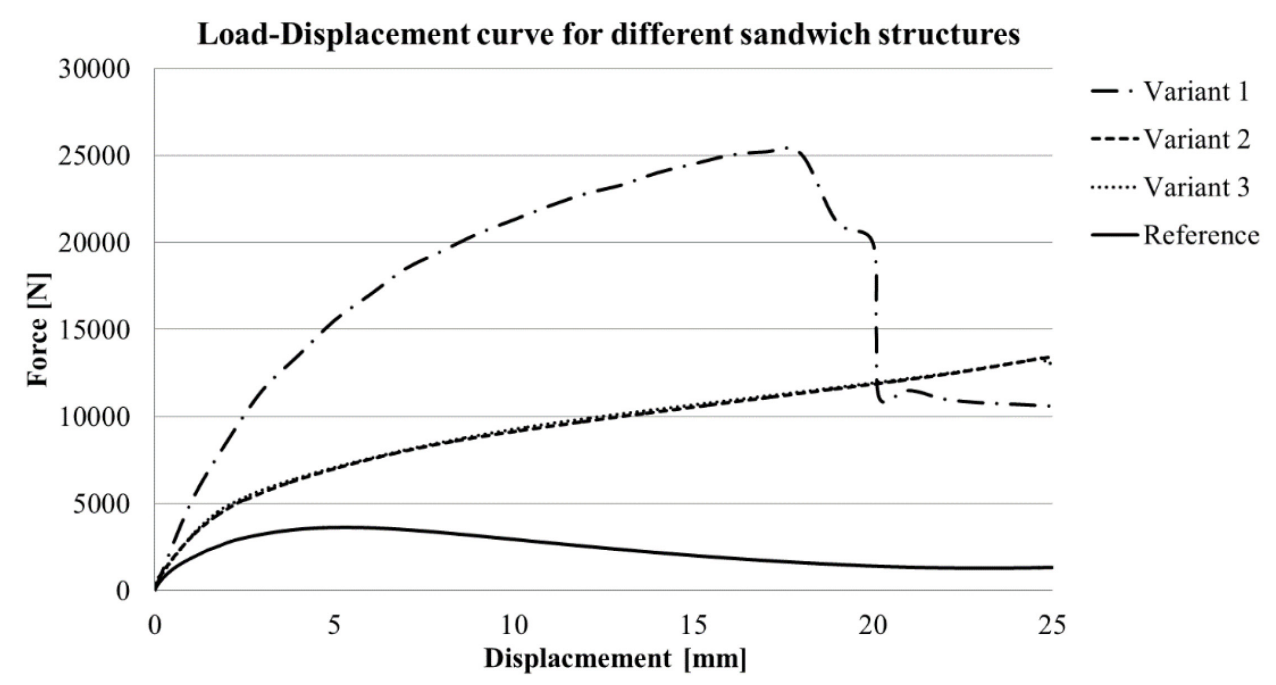

Fig. 2: Wooden composite sandwich structure: a) Profile geometries, b) Test setup, c) Material configurations, d) Force-displacement diagram

Aluminium is established when it comes to outer panels in the field of vehicle manufacturing and due to its low density and natural corrosion protection, is particularly suitable for the outer skin of a passenger capsule. In comparison to steel sheets however, relatively high material thicknesses have to be utilised when using aluminium sheet material in order to compensate for the lower rigidity [6]. In order to investigate the bracing effect of thin sheets, cambered wood-reinforced aluminium sheets were manufactured using a press process at TFF. For this purpose, aluminium sheets with a thickness of $0.6 \mathrm{~mm}$ were reinforced with veneer multilayer composites with a thickness of $2.5 \mathrm{~mm}$ and with different orientations (Fig. 3c). In relation to an aluminium sheet with a thickness of $1.5 \mathrm{~mm}$, the structure does not affect the weight. The samples were tested in the test facilities at DLR, as shown in Fig. 3a, b similar to the one used for the sandwich materials described above. 


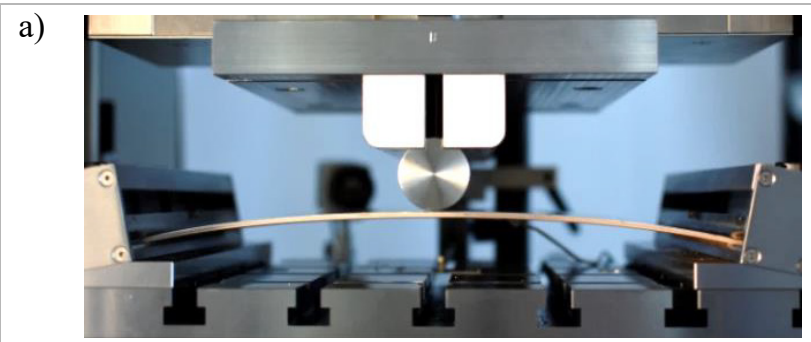

b)

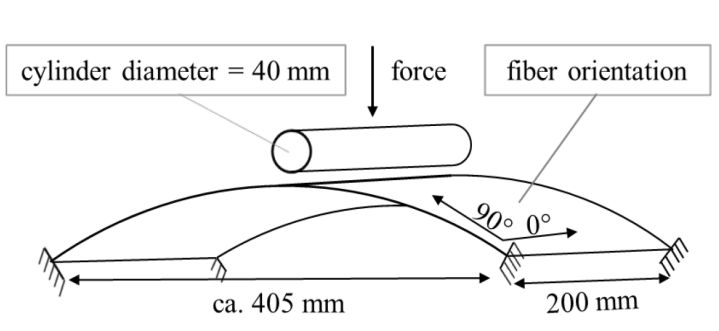

c)

\begin{tabular}{|c|c|c|c|c|c|c|c|c|c|c|c|}
\hline \multirow{5}{*}{ 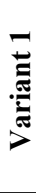 } & Layer & 1 & 2 & 3 & 4 & \multirow{5}{*}{ } & Layer & 1 & 2 & 3 & 4 \\
\hline & Material & $\overline{\mathrm{Al}}$ & $\mathrm{B}$ & $\mathrm{B}$ & $\mathrm{B}$ & & Material & $\mathrm{Al}$ & $\mathrm{B}$ & $\mathrm{B}$ & $\mathrm{B}$ \\
\hline & Thickness [mm] & 0.6 & 1.0 & 0.5 & 1.0 & & Thickness [mm] & 0.6 & 1.0 & 0.5 & 1.0 \\
\hline & Orientation & - & $90^{\circ}$ & $0^{\circ}$ & $90^{\circ}$ & & Orientation & - & $0^{\circ}$ & $90^{\circ}$ & $0^{\circ}$ \\
\hline & Measured weight [g] & & 3 & & & & Measured weight [g] & & 30 & & \\
\hline
\end{tabular}

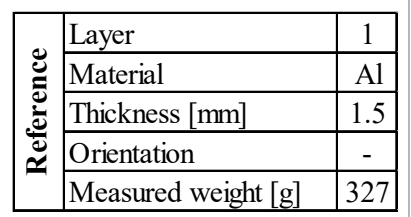

Aluminum (AW 5754 ): Al; Beech veneer: B; Glue: Jowat 680.20

d)

Force-displacement curve for reinforced alumnium sheets

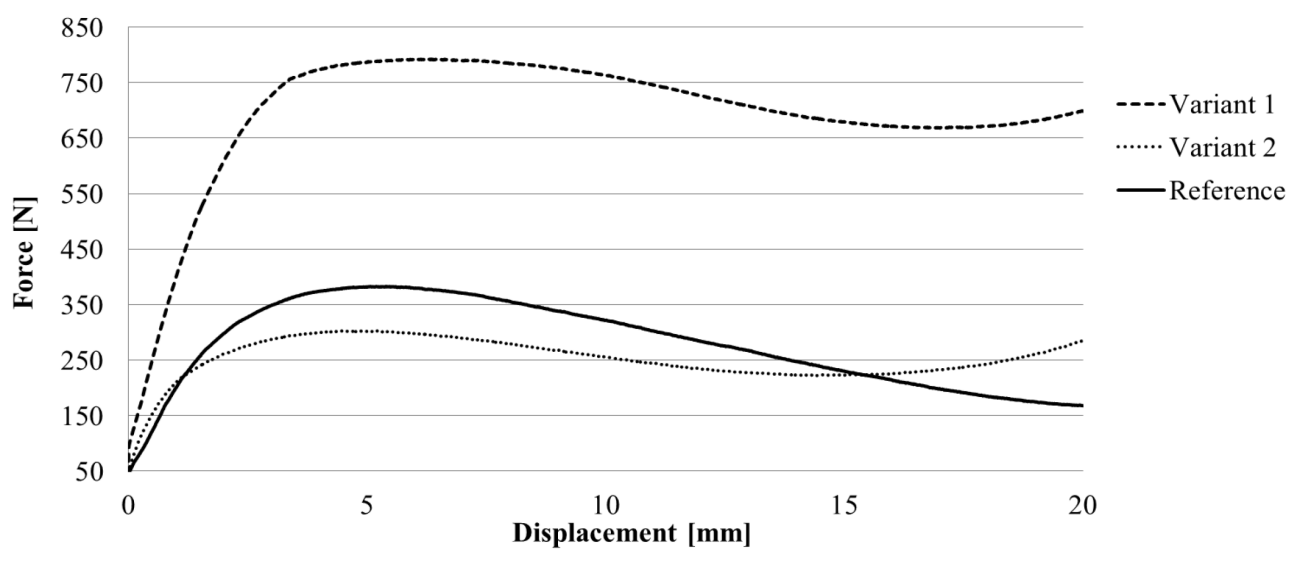

Fig. 3: Wood-reinforced aluminium sheets: a,b) Test setup, c) Material configurations, d) Forcedisplacement diagram

The testing carried out on the sheets show the strong influence of the orientation of the layers on the strength. In the case of variant 1 , the fibres of the first and third veneer layers are oriented in the pull and push direction, whilst the fibres of the second layer are oriented across this direction (see Fig. $3 \mathrm{c}$ ). In the case of variant 2, the fibres of the second veneer layer are oriented in the pull and push direction, whilst the fibres of the first and third layer are oriented across this direction. Variant 1 can absorb a load around twice as high as that of variant 2 before the first maximum force is reached. Once the sheets have been pushed beyond the middle position, there is another force increase in each case. This is because the stabilising wood layer does not fail and continues to stabilise the composite up to the maximum possible displacement of the trial of $20 \mathrm{~mm}$. In comparison, the reference shows a higher force level than variant 2. However, the increase in force in the deformation range over $16 \mathrm{~mm}$ is significantly greater in the case of the wood-reinforced sample.

High pressure loads occur in vehicle structures, in particular, in case of a crash - and the passenger compartment then has to be prevented from collapsing. In a capsule for conveying passengers, this function could be performed by pressure load paths, made from a wood hybrid material, running along the sides or the floor.

To test the pressure loads which have to be transferred, at WKI top-hat wooden profiles were produced with a material thickness of $7.5 \mathrm{~mm}$ with various layer structures. The profiles were then tested for pressure at the DLR. In order to be able to classify the results better, an aluminium profile with similar but not identical dimensions and weight, made from AW 5754, was also tested (see Fig. $4 a, b)$. The aluminium profile is therefore only used as an example for comparison and not as a true reference. It is used only to estimate the potential of the wooden profiles. 


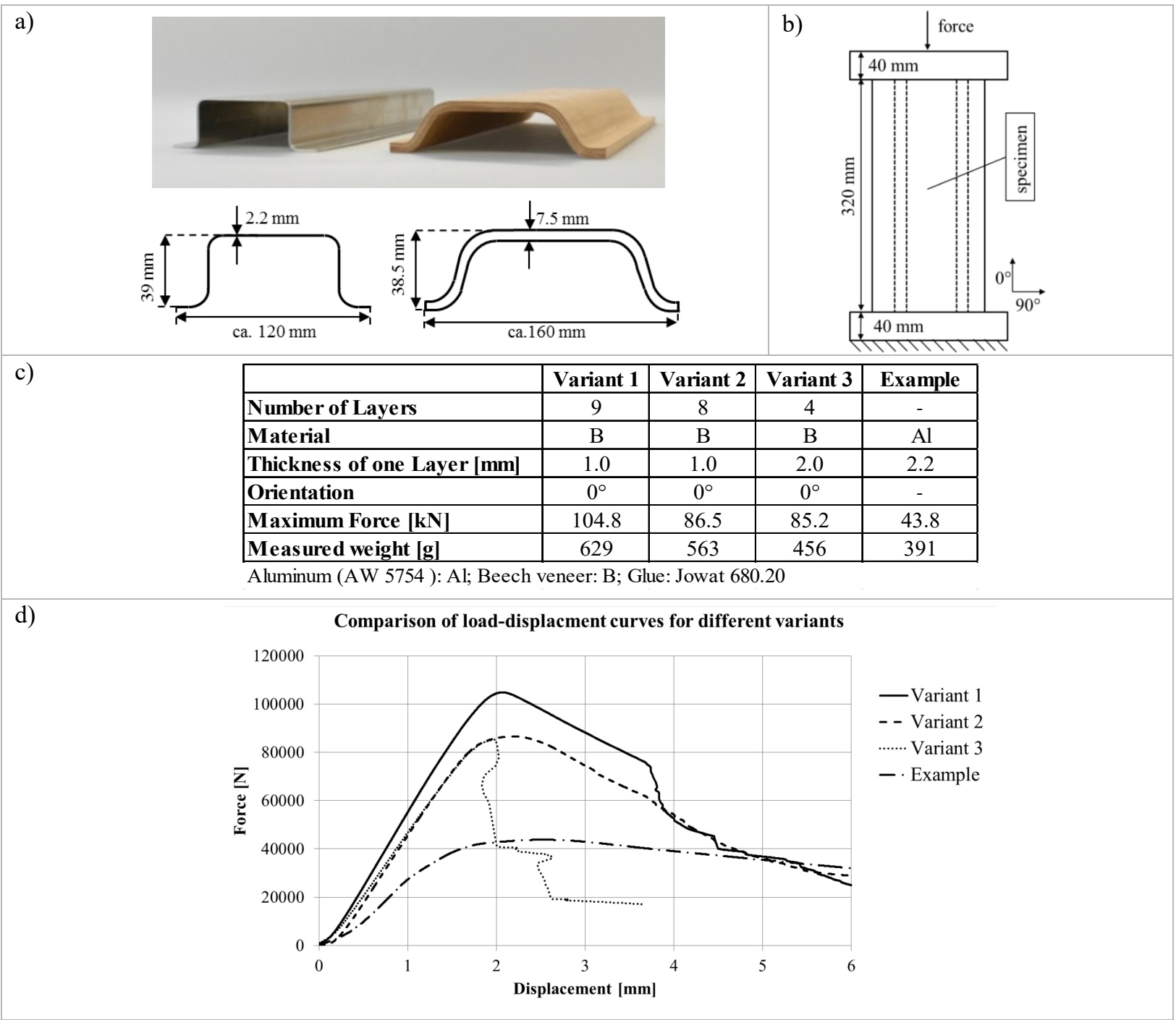

Fig. 4: Wooden profiles for pressure load conditions: a) Profile geometries, b) Test setup, c) Material configurations, d) Force-displacement diagram

Fig. 4c lists the tested layer structures in table form. The veneers were compressed during the manufacturing process. The strong influence of the compression is evident, particularly in variant 1 , in which the wood was compressed from $9.0 \mathrm{~mm}$ to $7.5 \mathrm{~mm}$ (see Fig. 4c, d). The maximum force under pressure for this variant stands at over $100 \mathrm{kN}$, but the weight of the profiles also increases. From variant 3 to variant 2, the number of layers was doubled from four to eight layers, and the layer thickness was halved. The additional adhesive joints also resulted in a higher component weight. Unlike variant 3 however, variant 2 does not fail abruptly. One reason for this may be the reduction of energy due to the failure and delamination of the additional veneer layers.

\section{Discussion}

As a result of testing the wooden composite sandwich structures (see Fig. 2), it was thus possible to influence the type of failure and the reproducibility significantly. When wood is used as sandwich core material, the wood is protected from ambient influences. The fact that the structure has a high inherent rigidity compared to pure steel sheet material and the thermal insulation is improved, are further benefits. When the core is manufactured separately, it can be given an additional structure, e.g. by introducing grooves, in order to save weight.

Numerous benefits can be obtained by using wood-reinforced aluminium sheets (see Fig. 3). The thermal insulation of the material is increased, and the acoustic properties are improved as a result of the damping effect of the wood. The hybridisation makes handling the thin aluminium sheets simpler. The use of the veneer multilayer composite means that the hybridised metal sheet can be adhered 
more easily to other materials because there is no longer a problem of an oxide layer forming on the inside of the sheet metal. The rigidity of the components is increased overall, and the aluminium content is reduced. The outer aluminium layer protects the wood from external ambient influences. Constructional measures also have to be implemented in order to make sure that no damage is caused to the multilayer veneer composite on the inside as a result of penetration from moisture.

Overall, the wooden profiles (see Fig. 4) have a significantly higher force level than the example for comparison made from aluminium. It is important to note that no locking layers were introduced i.e. so that all fibres run in the load direction. In practice this leads to increased component warping after production and has to be offset using locking layers, stabilising surfaces layers or constructional measures. The wooden profiles can transfer high axial loads and are thus particularly well suited for absorbing pressure loads. The profiles also have the advantage of a low thermal conductivity. Thanks to the material thickness and the high inherent rigidity of the wooden composite with a thickness of $7.5 \mathrm{~mm}$, joining elements can be introduced easily. In a further step, the influence of hybridisation can now be examined.

The individual components developed and tested in this way can be used to construct larger structures for roof or side wall structures, for instance Fig. 5 shows an example.

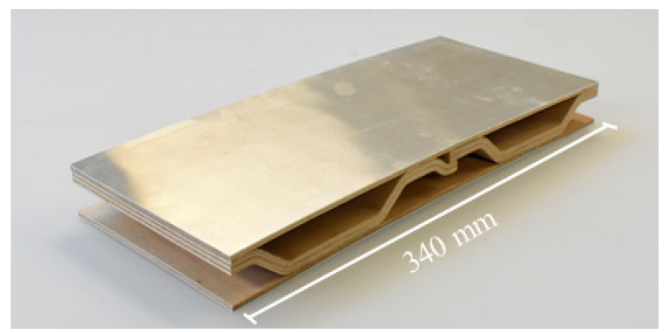

Fig. 5: Example of a wood-aluminium structure comprising wood-reinforced aluminium sheets and wooden profiles

\section{Conclusion}

The selected concepts show the high potential for wood in vehicle structures. The forces achieved in the presented concepts are clearly higher than those of each selected reference structure with the same weight. This was clear, in particular when substituting steel structure for an aluminium-wood composite. A number of further subjects are being considered within the For(s)tschritt project. These include, for instance, corrosion performance and process optimisation. The goal of the research plans is to qualify beech wood based multi-material systems for use in the vehicle structures of the future. The aim is to create economically and ecologically attractive alternatives to existing material solutions.

\section{References}

[1] C. Ulrich, H. E. Friedrich, J. Weimer, R. Hahn, G. Kopp und M. Münster, Technologies for a modular vehicle concept used in passenger and goods transport, submitted to 19. Stuttgart international symposium, Stuttgart, 2019.

[2] M. Ashby and D. Jones, Engineering Materials 2 An Introduction to Microstructres, Processing and Design, Burlington, Butterworth-Heinemann, 2006, pp. 306-316.

[3] Bayerisches Staatsministerium für Ernährung, Landwirtschaft und Forsten, Holzmarktbericht zum I.Quartal in Bayern, Bayerischer Waldbesitzerverband e.V., Bayern, 2018.

[4] U. Lohmann, Holzlexikon, Nikol, 2010, pp. 373-385.

[5] S. R. Reid and C. Peng, Dynamic Uniaxial Crushing of Wood, in: International Journal of Impact Engineering, p. 531-570, Vol.19 1997.

[6] H. N. Han and J. P. Clark, Lifetime Costing of the Body-in-White: Steel vs. Aluminum, JOMThe Journal of The Minerals, Metals \& Materials Society, pp. 22-28, May 1995. 